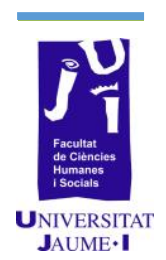

\title{
Two approaches to teach the preposition on
}

Nuria Flor Fabregat

al081314@alumail.uji.es 
As some studies suggest (Navarro 1998; Navarro, Campoy \& Caballero 2001; Silvestre 2009), the mastery of in, on, and at presents special problems for many Spanish students of English as a Foreign Language. In this project I have focused on the preposition on in order to check a different theoretical approach and an experimental approach at the same time.

Following the theoretical proposals by Navarro (1998), a same series of activities were prepared for two groups of intermediate level of English at the official school of languages in Castellón. The main and only difference between each group lies in the method employed to introduce the use of on. Thus, at the beginning of the lesson, the theory and the basic senses of on were explained with examples in the first group. In the second group, in contrast, some images were shown in order to experiment the common senses or uses of on mentioned by themselves without theory.

Apart from the activities, proficiency assessments were developed in order to know the level and mastery of the use of prepositions on, in and $a t$, with a special focus on the basic senses of on with examples. These proficiency assessments were filled in by students at the beginning and at the end of the class.

After the implementation of the lessons in either group following these two different methodological procedures, data were gathered from students and the results concerning the preposition on were compared in both groups in terms of correct answers.

Finally, the general results of this study show the benefits of the experimental and the theoretical approach to the teaching of on particularly. Then, the conclusions show the convenient approach for the context of my project.

Key words: The preposition on, theoretical approach, experimental approach, two groups, intermediate level.

\section{Introduction}

Many students of English as a Foreign Language (henceforth EFL) find difficulties when they are learning English prepositions. A point in case is the correlation between the English prepositions in, on and at and the Spanish preposition en. Because English and Spanish systems overlap in the encapsulation of space relationships in terms of prepositions like these, Spanish EFL students often find problems in learning their correct use of them in context (Navarro, Campoy \& Caballero 2001).

Traditional approaches to preposition teaching in English are often reduced to a series of rules and typical examples, but the students often take pains in applying these rules correctly in different contexts.

Besides, there are different types of prepositions, and the students 
should know what prepositions are mainly used to describe time, direction, means, manner, state, quantity, purpose, etc. Thus, identifying the nature of a preposition would help a student to understand the appropriate preposition usage and choice (Lindstromberg,1998).

Personally, previously as a student but especially lately during my internship, I have been able to observe that the students do not know which prepositions are the correct option when producing oral or written English (e.g. compositions) in many cases. Although they know about the existence of the "rules" to follow when dealing with prepositions, they do not have a good knowledge of the nature of the prepositions that they are using together with their main senses and contextual uses. In the case of compositions they seem to write by intuition on the basis of their knowledge when I asked them initially. So, it seems clear that they need more practice and to do more exercises after all.

The problem is perhaps the kind of practice that they need to take. Should this be based on the learning of "rules" and drills or should this practice rely on an approach that focuses on a more natural way to learn space relationships by focusing on the nature and contextual uses of prepositions?

This study departs from the standpoint summarized on the second question. From a cognitive linguistics perspective - and as a continuation of the line of research expanded by studies like Silvestre (2009, forthcoming) and Alonso (2011) - I shall devise and check the convenience of two different methodological approaches related to the approach to prepositional polysemy developed initially by Navarro 1998. More concretely, I shall focus on the preposition on in the development of the activities in the classroom.

The particular objectives of my research together with a detailed account on the procedures followed to carry out this study can be found under the objectives section and the method section below. Before diving into these sections, and for the sake of clarity, it seems necessary to provide a brief description of the theoretical bases that sustain this approach.

\subsection{THEORETICAL BACKGROUND}

The system by which we conceptualize phenomena is, according to Lakoff and Johnson (1980) and Lakoff (1987), organized in terms of categories and, the structures by which such categories are formulated, are, namely, Idealised Cognitive Models or ICMs in short.

Firstly, our physical and social experiences appear to play a role in how our conceptual system formulates the sets of elements which are known as cognitive categories. The prototype is the ideal model by which any cognitive category can be defined. A category is then compared to this prototype along a radial structure in order to define to what degree it resembles the ideal model. The closer it agrees with this model the easier 
it is to identify it with this ideal one. The more peripheral members of any model or category are also likely to be members of other categories in that they share similar features. Cognitive categories have fuzzy boundaries, in that, they can be drawn up according to the demands of the conceptualization of reality.

Secondly, ICMs function to allow our cognitive system to categorise, to organize, to understand and to represent our knowledge of the external world. They are, in short, tools by which we can create mental representations of the external world. Depending on which ICM we use we can get differing representations of the same real-world phenomena.

In the cognitive paradigm, prepositions are considered as particles which relate two elements: the trajector and the landmark are referred to as the TR and LM in short (Langacker, 1987). The trajector is the most significant entity, it can be changed more easily from one place to another and it is usually situated before the preposition. However, the landmark is the entity to which the trajector is related. It is situated after the preposition and it is the point of reference for the trajector. For example: The bottle is on the table. The bottle is the TR which can be moved easily and its resting side falls across the LM, in this case, the table, which works as a supporting point for the TR.

Prepositions, in cognitive linguistics, are considered as "linguistic categories" themselves encompassing a series of elements (meanings, senses) arranged in the structure of a radial category, with a prototype and peripheral members; they are, therefore, polysemous elements.

The following is a representation of the radial network for on proposed by Navarro (1998):

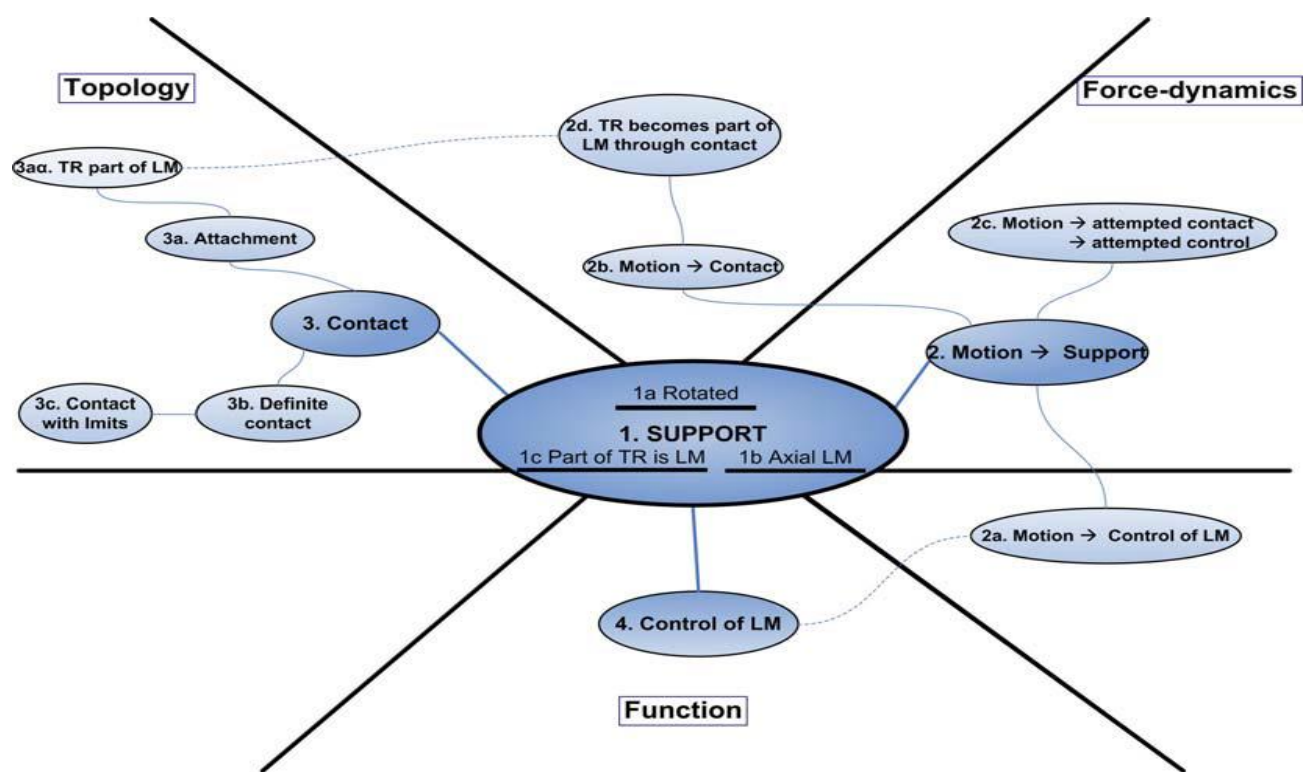

Figure 1. Radial category for On. (Adapted from Navarro, 1998: 219, in Silvestre 2009:69)

The central element of this network represents the most significant sense of each preposition. Independently of the location of the senses within 
the network, all of them are multidimensional in that the three aspects of construal are always present.

These aspects are configured in a relationship of equilibrium at the very centre of the network. Then, any sense located in a particular area (as marked in Figure 1) is assumed to exhibit an unbalanced configuration where one or two of these aspects become more emphasized. More peripheral senses share features among themselves and with more central ones in terms and are arranged in the network in terms of family resemblance relationships.

In order to take into account the relationship between these three prepositions and the dimensions or senses, I have explained the most important theoretical points. This will provide for a better understanding of the next pages. The next subsection introduces the main objectives of my research.

\section{Objetives}

As is well known, English prepositions play a role in the expression of many key notions besides those pertaining to physical objects in their arrangements, orientations and so forth.

A preposition serves to connect its object with the rest of a sentence. In doing so, a preposition indicates the relationship of the idea expressed in the prepositional phrase to the ideas expressed in the rest of the sentence (Lindstromberg,1998).

Although there are less than one hundred English prepositions, they do not take endings, and even if the structure of most prepositional phrases is simple, the use of English prepositions is very complex. The reasons for this are that most prepositions have more than one meaning, as described, for example, in the prepositional approaches for polysemy as Navarro's.

Many prepositions can also be used as adverbs, in hundreds of idioms, many adjectives, nouns, and verbs must usually be followed by certain prepositions, and there are hundreds of phrasal verbs formed from combinations of verbs with adverbs and prepositions (Lindstromberg,1998). This makes things more complex for students to master their use.

According to previous studies (Silvestre, 2009), the preposition on causes confusion and difficulty with other particles such as in or at for the EFL learners because of the fact that, there is not a direct correspondence between the categorization linguistic systems of the spatial relations in both languages, English and Spanish. So, the prepositions are not equivalent. The focus of analysis of this project is placed on the preposition on in order to obtain more information of the particular intricacies of its use in this respect. The study, however, does not disregard the interaction of the uses of on with in and at in particular contexts, which is reflected in some of the activities proposed. 
The model proposed by Navarro (1998) offers a cognitive approach to the different meanings and uses of on, and four of the most salient senses are the following (cf. Figure 1):

- Contact

- Support

- Motion ending in support

- Control of landmark

The main and essential objective of the research conducted in this study is to check two different teaching methodologies for this approach and to know whether their implementation on two groups of intermediate-level students of EFL yields significant differences in their overall performance.

The basic objective, therefore, will guide the method employed in the study. In order to compare two different implementation methodologies, departing from these four main senses of on, and following previous studies about the implementation of this model in the classroom like Alonso (2011) or Navarro, Caballero \& Campoy (2001), two groups ("theoretic" and "experimental") of students of the same level were set, and a series of tools and materials were devised.

\section{Material and Methodology}

After finishing the lessons of the master teaching period I had to do an internship. I was at the official school of languages in Castellón where there were several levels (basic, intermediate and advanced) and students from different ages and background.

In my case, I implemented my activities on two groups of the same level, the fourth course; that is an intermediate level. In the first group, the students were more participative and enjoyed asking questions to the teacher. But in the second group, most of the times there were students who liked listening to other classmates and doing listening activities instead of speaking. Then, I could provide the two types of methods in these two groups of intermediate level during two lessons.

In the theoretic group there were eighteen students who were studying at university, so they were younger and needed the final certificate for their studies and CVs. In the other group, the experimental one, there were fifteen students and most of them were students who had been working in companies and they needed to pass the final certificate for their jobs.

The main tools and materials are: an (i) initial and final assessment test, (ii) support materials for the theoretical and "experimental" lesson, and (iii) a series of activities to be implemented in class between each assessment test were devised. 
In the initial and the final assessment tests, which were placed at the beginning and the end of each lesson, included two activities (Q1 and Q2) and some questions to reflect on the difficulty of prepositions in English (Q3a and Q3b).

I had chosen these questions because I wanted to learn about the students' previous knowledge of these prepositions and if they could understand the different senses of on by themselves.

After doing the initial assessment test, one group of students was allowed to read the description with the main senses, with the help of some materials related to a theoretical session. In the other group, the students could learn themselves the main senses on the slide projector with images. After learning the main senses, both groups did the same activities. These are of four different kinds.

The common procedure is: firstly, the students completed a proficiency assessment test in order to know if they understood when the prepositions on, in and at were used. After that, I introduced the most important senses in which the preposition on was being used following two different methodological procedures, with the aim of comparing the results related to this preposition at the end. Once the students had understood the concepts, they continued with the activities.

In one of these activities they had to write and draw the trajector and the landmark in each context. In a different one the students wrote and did a dialogue with the correct prepositions and punctuation; it was possible to read aloud too. Finally, the activities also involved them in matching the senses and making sentences with prepositions.

In order to finish the lesson, they completed the final assessment test, whose extracted data would allow me to ascertain whether they had improved their general knowledge of the preposition on. Any differences in this concern would be indicative of the efficacy of either teaching method, that is, the lesson with the explanation of the theory or the other one involving direct experimentation by themselves.

As there were two groups to introduce the senses, I explained them in a different way. I tried to clarify the theory at the beginning in order to pay attention to the different senses and the preposition on in a real context.

In the theoretic group I provided the students with a basic layout containing schematic information on the main sense of on; it was accompanied by an explanation with examples in case of doubts. They knew the main uses and senses in order to start the following activities. So, they could learn the name of the sense and the schema (graphic representation of the TR-LM relationship related to each sense) and in the end there were some examples for learning in a context.

In the experimental group, the students looked at some images without theory and I also asked them some questions such as: "What do these images have in common?" or "What is the most emphasized sense?". Then they did not have any linguistic or conceptual interference but they experimented the senses by themselves with the images 
mentioned earlier. So, first they had some images only, and after they guessed the correct senses saying sentences with the examples shown corresponding to each sense. In this implemented method, unlike in the first group, I began with the examples and not with the name of the senses.

INITIAL AND FINAL ASSESSMENT: Q1) Initial assessment. ON/ IN/ AT

1. He preferred sleeping .... bed with his head .... a pillow.

2. She sat down .... the table shaking her head.

3. The primitive quality of his drawings, akin to that of graffiti scratched .... the cave wall, is equally well known.

4. The hustler would have the table ready and a pot of coffee hissing .... a stove.

5. The chicken had been marinated .... brandy.

6. The fruit is allowed to mature .... the tree.

7. .... spring and summer evenings people leave their shops and houses and walk up through the lanes.

8. They tasted good to him, so he brought some to breakfast to eat .... his cereal bowl with milk and honey.

9. I was back .... ten minutes.

10 . She is studying chemistry ... university.

11 . Write your name ... the top of the page.

12. All the players shook hands ... the end of the match.

Q2) Match the following sentences with the same sense: contact, support, motion ending in support or control of landmark.

1. There is a beautiful picture hanging on the wall.

2. He had his red jumper on.

3. The helicopter landed on the field.

4. Put the dish towel on the radiator to dry.

5. The little bear managed to survive on a tiny floating piece.

6. He threw the ball on the grass.

7. Advertisements influence on children.

8. You can improve your test scores if you really work on it.

\section{Q3a) QUESTIONS}

1. Do you know why have you used each preposition in these sentences? (Because of knowledge or intuition)

2. Along these sentences, have you found some more difficult than others? Which one(s)?

3. How have you studied prepositions until now? (using a book in class or at home on your own)

4. What do you think of this way of studying prepositions? Was it effective or suitable? 
5. Do you usually have some doubts about how to use prepositions?

6. Which preposition do you think is the most difficult for you?

\section{Q3b) QUESTIONS}

1. Do you know why have you used each preposition in these sentences? (Because of knowledge or intuition)

2. In these senses, have you found any sense more difficult than other? Which one?

3. How would you have liked to study prepositions?

4. Have you understood better the use of prepositions with these activities?

5. Have you found this new vision on prepositions useful? If yes, in what ways? If not, why?

\section{THEORY AND EXPERIMENTAL LESSON: INTRODUCTORY MATERIALS}

\begin{tabular}{|c|c|c|}
\hline $\begin{array}{l}\text { Theory: } \\
\text { Sense }\end{array}$ & SCHEMA & DESCRIPTION \\
\hline CONTACT & Extracted from Navarro (1998:200) & $\begin{array}{l}\text { The Trajector and the Landmark } \\
\text { hold a relation of contact } \\
\text { between the supporting side of } \\
\text { the Trajector and the external } \\
\text { side (surface) of the Landmark. } \\
\text { - She was warming her } \\
\text { hands on the cup. } \\
\text { - There is a label on the } \\
\text { bottle. } \\
\text { The dish towel was left } \\
\text { on the radiator to dry. }\end{array}$ \\
\hline SUPPORT & Extracted from Navarro (1998:182) & $\begin{array}{l}\text { The Trajector finds some kind of } \\
\text { support thanks to the presence } \\
\text { of the Landmark. } \\
\text { - The book is on the table. } \\
\text { - Pictures of landscapes } \\
\text { were on the walls of } \\
\text { every single room of his } \\
\text { house. } \\
\text { There is a fly on the } \\
\text { ceiling. }\end{array}$ \\
\hline
\end{tabular}




\begin{tabular}{|c|c|c|}
\hline $\begin{array}{l}\text { MOTION TO } \\
\text { SUPPORT }\end{array}$ & $\begin{array}{ll}\text { Landmark } & 1 \\
\text { Extracted from Navarro (1998:195) }\end{array}$ & $\begin{array}{l}\text { The Trajector shows some kind } \\
\text { of motion that has a end once it } \\
\text { gets in contact with the } \\
\text { Landmark (its surface), and in } \\
\text { position where the Trajector } \\
\text { gains control over itself. } \\
\text { - He threw his dirty clothes } \\
\text { on the ground before he } \\
\text { had a shower. } \\
\text { After a long trip, the } \\
\text { family of storks perched } \\
\text { on a huge tree branch. } \\
\text { The plane landed on the } \\
\text { field. }\end{array}$ \\
\hline $\begin{array}{l}\text { CONTROL OF } \\
\text { LANDMARK }\end{array}$ & varro (1998:208) & $\begin{array}{l}\text { The Trajector has a control over } \\
\text { the Landmark or the situation } \\
\text { described itself. } \\
\text { - Advertisements influence } \\
\text { on children. } \\
\text { - You can improve your } \\
\text { test scores if you really } \\
\text { work on your subject. } \\
\text { - He is on the drums. }\end{array}$ \\
\hline
\end{tabular}

Figure 2. Theory: description of the main senses.

\section{IMAGES EMPLOYED IN THE “EXPERIMENTAL” APPROACH GROUP}

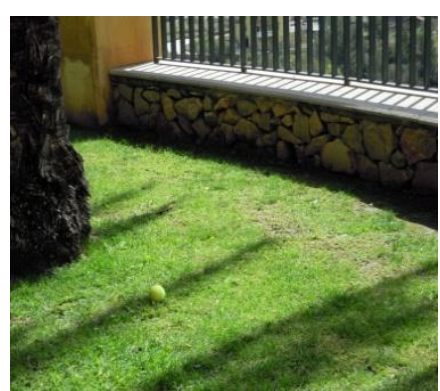

Figure 3

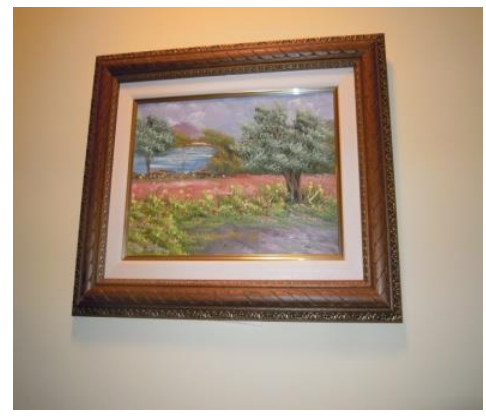

Figure 5

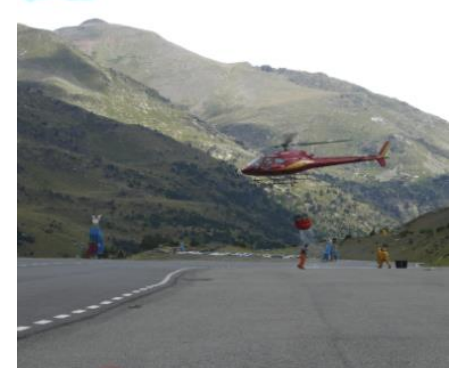

Figure 4

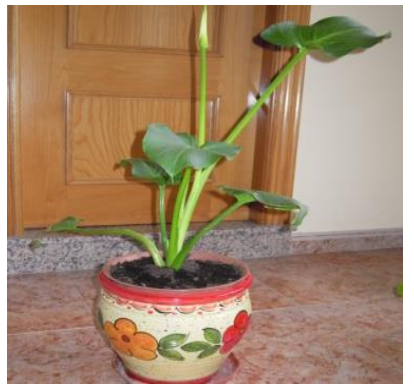

Figure 6 


\section{ACTIVITIES ON}

1) Theory: Basic chart with the main uses of ON.

\section{SENSES}

- Contact

- Support

- Motion ending in support

- Control of landmark

2) Read the following sentences and try to write and draw the correct senses and as well as the trajector and the landmark. In pairs, compare the answers.
A. The lamp is on the table.
B. A fly is on the ceiling.
C. He was warming his hands on the cup, although the room was heavy with heat.
D. There is a dirty mark on the wall / on your shirt.
E. In Britain we drive on the left hand side of the road.
F. Here is a shopping list. Don't buy anything that's not on the list.
G. Our flat is on the second floor of the building.
$H$. The bus was very full. There were too many people on it.
I. I didn't watch the news on television, but I heard it on the radio.
J. He is away at the moment. He is on a cruise in Italy.

3) Imagine you are on holidays. In pairs write a dialogue of $\mathbf{1 0 0}$ words about an experience on your trip. Check that you have used the prepositions (on, in, at) correctly.

-Do you practice any sport? when do you practice it?

-Describe your hotel. 
4) Match the following senses or headings with the sentences.

\begin{tabular}{|l|l|}
\hline CONTACT & SUPPORT \\
\hline MOTION TO SUPPORT & CONTROL OF LANDMARK \\
\hline
\end{tabular}

1. The cat is on the mat.

2. The plane landed on the field.

3. Don't you have to spend any time on your ranch?

4. He was warming his hands on the cup, although the room was heavy with heat.

5. I sat down on the grass yesterday.

6. My friend is a great musician. He is on the drums of a very well-known band.

7. They throw the peel on the floor.

8. There is a label on the bottle.

5) Try to make sentences with the following information.

1. leave - Heathrow - 6 o'clock

2. arrive - Madrid - 8:40

3. watch - the news - television

4. then go - Valencia - a train

5. get to - Valencia - Saturday evening

6. fly back - London - Monday morning

7. speak - her - the phone

8. have - go - a diet

9. pay - the bill - cash

10. swim - the river - summer

\section{Results}

In the first activity of the assessments, the students obtained 32 correct answers with the preposition on in the initial and 34 in the final assessment. Then, it is shown the little improvement in this group since according to the students, the theoretical approach was seen as unreal approach.

In the second activity, the students got 18 correct answers in the sense of support and 19 in control of landmark in the initial assessment. In the final assessment they got 29 in the sense of support and 29 in control of landmark. Then, they improved the sense of support and control of landmark in the final because they practised the theory and the senses at the beginning. 


\subsection{INITIAL AND FINAL ASSESSMENT IMPLEMENTED ON BOTH GROUPS: DATA CROSSED}

In the first activity, the students of the experimental group obtained a high progress with the preposition on, 36 in the initial assessment and 52 in the final assessment. But in the theoretic group, the only relevant improvement is with the preposition in and at. Since they obtained 32 correct answers of on in the initial assessment and only 34 in the final assessment. So, the experimental group obtained better results.

In the second activity, the students of the experimental group improved the sense of support with 19 and 22 correct answers in control of landmark. But in the theoretic group, they got better results in the same senses, 29 correct answers in the final assessment. One of the reasons might be because they practised more the senses and the theory at the beginning.

\begin{tabular}{lll}
\hline & $\begin{array}{l}\text { FIRST } \\
\text { ACTIVITY: } \\
\text { PREPOSITIONS }\end{array}$ & $\begin{array}{l}\text { SECOND } \\
\text { ACTIVITY: } \\
\text { SENSES }\end{array}$ \\
\hline $\begin{array}{l}\text { EXPERIMENTAL } \\
\text { GROUP: }\end{array}$ & $61 \%$ & $60 \%$ \\
INITIAL & & \\
ASSESSMENT & & \\
EXPERIMENTAL & $63 \%$ & \\
GROUP: FINAL & & \\
ASSESSMENT & & $45 \%$ \\
THEORETIC & $53 \%$ & \\
GROUP: & & $72 \%$ \\
INITIAL & & \\
ASSESSMENT & & \\
THEORETIC & & \\
GROUP: FINAL & & \\
ASSESSMENT & & \\
\hline
\end{tabular}

Table 1. General results. Percentages.

In general, in the experimental group show $60 \%$ in the initial assessment and $62 \%$ of correct answers in the final assessment. In the theoretic group, as shown in Table 1 they got $45 \%$ of correct answers in the initial assessment and $72 \%$ in the final assessment.

\subsection{RESULTS: GENERAL PERFORMANCE ON THE THREE PREPOSITIONS}

In the assessment tests, the first activity was about filling the gaps with the three prepositions in, on and at. Then, according to Table 1, the experimental group improved the correct answers from $61 \%$ in the initial assessment to $63 \%$ in the final assessment. But the theoretic group had different percentages, it was 53\% in the initial assessment and $58 \%$ in the final assessment as shown in Table 1.

In the experimental group, the average age was 35-40 and many of 
the students had studied English grammar for several years. Then, they could complete the gaps with prepositions in an intermediate level more easily. As in this class I showed them some images, they paid attention to the preposition on with examples.

In fact, I also realized that the best results were: in the initial test they had 44 correct answers of the preposition in because it is likely one of the most used in compositions according to the students. However, in the final they had 52 correct answers of the preposition on since they had been practicing with the main senses of on.

On the other hand, the theoretic group did not get a high mark since the average age was 20, they were younger and they also had more doubts about which preposition was the best in many sentences.

Indeed they have learnt these prepositions in different contexts during my lessons and the preposition in was used in many cases correctly. In the initial they had 48 correct answers of the preposition in and in the final they had 52 correct answers. Although it is one of the most difficult aspects in English for them, they have commented the only way to know the correct preposition is to practice in writing and speaking skills after all.

Finally, according to the table, the students of the experimental group have obtained $63 \%$ and $62 \%$ in the final assessment. They have had better results in the first exercise about filling the gaps with the three prepositions.

On the other hand, in the theoretic group the students have obtained $58 \%$ and $72 \%$ in the final assessment. They have had better results in the second exercise about the main senses of the preposition on (contact, support, motion ending in support and control of landmark).

\section{Conclusions}

This project has taken me several months to cover all the sections and the results, after giving the lessons at the official school of languages.

After the lessons, I found that teaching grammar is not something trivial. Due to its learning process, teachers need to come up with interesting teaching techniques. At the beginning, it might take a long time to come out with a topic that attract the students.

As suggested in the objectives set for this study, its main purpose is to obtain the information about the applicability of two different teaching methods of Navarro's approach to prepositional semantics by way of devising a series of materials and implementing them in two different groups of students. In the light of the results presented, it seems safe to come to the conclusion that it has been a good study, since there were two groups and two methods have been imparted and compared, and results have been drawn accordingly.

As far as I am concerned, the only way to learn a language is to practice and to do exercises. This is the reason because I prepared some activities and the assessments at the beginning and at the end of the 
lessons. Since it is a process, the students must follow the steps to acquire a certain level needed for their careers. In this way, it is known whether the students might be able to answer the questions and learn new concepts at the same time.

After carrying out the project, it is shown that the students have improved the knowledge of prepositions and as I focused on the preposition on, they have learnt the main senses. Although most of them explained that it is a complicated topic for them and then they would need more practice, there is a benefit and a progress after all.

In both groups, taking into account their answers and comments, they have understood the sense of support and control of landmark, since they have had more right answers in these senses finally. However, the students have found difficulties in the senses of contact and motion ending in support. Some of them have not known in which sentence is represented the sense of contact or support. These are, therefore, areas to take into account in order to perfect the classroom application of this approach to prepositional semantics.

Thus, the number of correct answers have increased enough which means that the students have learnt something else. According to the method used, some students have preferred beginning a lesson with images and experiment by themselves. But some others who are used to reading the theory first of all in many courses, explained to us that the theory would be necessary. Finally, most of them agreed to make a combination of the theory and as well as the practice with images. This is an interesting suggestion that should also be taken into account in future studies.

\section{Bibliography}

Lakoff, G. \& Johnson, M. (1980): Metaphors We Live By. Chicago/London: Chicago University Press.

LAKOFF, G. (1987): Women, Fire, and Dangerous Things: What Categories Reveal About the Mind. Chicago: University of Chicago Press.

LANGACKER, R.W. (1987): Foundations of Cognitive Grammar. Volume I: Theoretical Prerequisites. Stanford: Stanford University Press.

LINDSTROMBERG, S. (1998): English Prepositions Explained. AmsterdamPhiladelphia: John Benjamins.

MuRPhy, R.(2003): English Grammar in Use. Intermediate level. Cambridge University Press.

Navarro, I. (1998): A Cognitive Semantics Analysis of the Lexical Units AT, $O N$, and IN in English. Ph.D. Dissertation. Castelló de la Plana: Publicacions de la Universitat Jaume I de Castelló.

- (1999): «The Metaphorical Use of On». Journal of English Studies 1: 145164. 
NAVARRo, I. \& TRICKER, D. (2000-2001): A comparison of the use of AT, IN, ON by EFL students and native speakers. Revista española de lingüística aplicada, Vol. 14: 295-324.

NAVARRo, I. (2006): "On the meaning of three English prepositions». In: I. Navarro \& N. Alberola (Eds.), In roads of Language, Essays in English Studies, 167-179. Castelló: Publicacions UJI.

NavarRo, I., Campoy, M.C. \& Caballero, R. (2001): «Thinking with English Prepositions and Adverbs». In: Docència Universitària: Avanços Recents. Primera Jornada de Millora Educativa de la Universitat Jaume I, 243-252. Castellón: Publicacions de la Universitat Jaume I de Castelló.

Silvestre, A.J. (2009): Particle Semantics in English Phrasal and Prepositional Verbs: The Case of In and On. Saarbrücken / Beau-Bassin: VDM-Verlag.

Silvestre, A.J. (forthcoming): Multidimensional polysemy of the preposition into. Paper submitted for publication to Folia Linguistica.

WilLIAMson, M. (1985): Follow me. Drills. BBC English courses. Editorial Alhambra.

Website:

Cambridge Dictionaries online : http://dictionary.cambridge.org/ 